\title{
ДИАГНОСТИЧЕСКАЯ ЗНАЧИМОСТЬ РАКОВО-ЭМБРИОНАЛЬНОГО АНТИГЕНА ПОСЛЕ ХИРУРГИЧЕСКОГО УДАЛЕНИЯ ОПУХОЛИ тОЛСТОЙ кИшкИ
}

\author{
Хасигов Алан Владимирович \\ д.м.н., доцент \\ Гагулаева Кристина Владимировна \\ Батыров Казбек Ахмедович \\ Эдилов Расул Умарович \\ ФГБОУ ВО СОГМА
}

Аннотация: В данной статье рассматривается одна из актуальных проблем частоты рецидива онкологической заболеваемости по раку толстой кишки, после проведения хирургической операции по удалению опухоли. Целью исследования является: определение значимости в ранней диагностике рецидива рака толстой кишки по уровню такого онкомаркера, как РЭА-раковоэмбриональный антиген. Смыслом выбора темы для данного исследования послужил тот факт, что численность больных данным заболеванием растёт с каждым годом, а смертность от рецидива после адекватно выполненных оперативных вмешательств в Республике Северная Осетия-Алания возросла до $7,1 \%$ среди онкологических заболеваний за последние 3 года по данным международного журнала прикладных и фундаментальных исследований. Уровень РЭА как раз и является критерием ранней диагностики послеоперационного рецидива, и играет огромную роль в выборе дальнейшей тактики лечения. Материалом для исследования послужил анализ историй болезней с данным диагнозом, которым была выполнена адекватная радикальная операция по удалению опухоли, на базе ГБУЗ РОД 1-ого хирургического отделения с 2016 по 2020 год.

Ключевые слова: РЭА-раково-эмбриональный антиген, рецидив, диагностика, рост заболеваемости, ономаркеры, рак толстой кишки, онкологический диспансер, истории болезни.

Диагностика на данный момент является важным аспектом в развитии клинической медицины. На сегодняшний день ни одна отрасль медицины не справляется без диагностической персонализации, так как на передний план выходит понятие «доказательность медицины». То есть любой диагноз, или же 
вывод, должен иметь обоснование, которое базируется на диагностических критериях. Диагностика особо важна в онкологической отрасли клинической медицины. За основу исследований взята именно сфера онкологии по той причине, что смертность неимоверно высока, и растёт с каждым годом, не только в Республике Северная Осетия-Алания, но и во всём мире. В последние годы, по статистическим данным ГБУЗ РОД, идёт прогрессивный рост численности по раку толстой кишки, поэтому в данном случае это является актуальной проблемой. Диагностика на данном этапе медицинской отрасли одно из основных аспектов, который помогает поставить не только правильный диагноз, но и в дальнейшем вести мониторинг данного патологического процесса в организме, его характер, прогрессирование. Особенно это значимо в сфере онкологии, так как зачастую, для того чтобы понять исход операции, ввести контроль, после различных видов лечения, будь то радикальная операция или же химиотерапия, одним из основных показателей для ранней диагностики является определение титра онко-клеток, так называемых онкомаркеров.

Для каждого заболевания существует свой «пул» онко-клеток, которые характеризуют его течение. Мы решили изучить конкретный онкомаркерраково-эмбриональный антиген - РЭА. Который, как мы выявили в ходе статистического анализа, имеет немаловажную роль в ранней диагностике злокачественных новообразований толстой кишки. Особо важным остаётся его роль в послеоперационном периоде, так как определение титра РЭА ,зачастую, является единственным методом раннего и своевременного определения прогрессирования процесса. Это является злободневной проблемой для нашей республики, так заболеваемость по раку толстой кишки возрастает, а ранняя диагностика зачастую страдает, Что увеличивает инвалидизацию и увеличивает стойкую нетрудоспособность населения.

Для рака толстой кишки одним из наиболее значимых маркеров является уровень РЭА-раково-эмбриональный антигена. Целью нашего исследования является анализ собранных нами статистических данных на базе ГБУЗРОД г. Владикавказ с 2016 по 2020 год, так как рост смертности наблюдался именно за этот временной промежуток, и определить значимость РЭА для диагностики рецидива при раке толстой и прямой кишки после проведения радикального оперативного вмешательства По удалению опухоли.

Раковый эмбриональный антиген (РЭА) - это вещество белковой природы, которое используется в лабораторной диагностике как маркер 
онкологических заболеваний. У здорового человека он находится в очень малых количествах. В периоде внутриутробного развития он синтезируется в органах желудочно-кишечного тракта и стимулирует размножение клеток. Определение уровня РЭА используют для диагностики ряда злокачественных опухолей, в первую очередь рака толстой и прямой кишки, а также желудка, пищевода, гортани, шейки матки и даже щитовидной железы. Если в норме содержание РЭА в венозной крови очень низкое, то при онкологических заболеваниях оно резко поднимается и может достигать очень больших цифр. Но не стоит забывать, что его уровень повышается также у курящих людей.

В норме его содержание в крови:

У некурящих: 0,00 - 5,00 нг/мл;

У курящих: 0,00 - 5,70 нг/мл.

С помощью этого маркёра и определением его уровня в крови мы можем судить об эффективности проводимого лечения. После выполнения оперативного вмешательства по поводу рака толстой кишки его уровень возвращается к норме в течение двух месяцев. В дальнейшем по окончании лечения и выписке пациента необходимо наблюдать и брать анализ крови на определение уровня РЭА каждые 3 месяца в первые два года, на сроке 3-5 лет раз в полгода для контроля состояния пациента после лечения, а также выявления рецидива на ранних этапах.

В ходе нашего статистического исследования, нами были проанализированы 258 историй болезней пациентов с данным диагнозом в период с января 2016 по декабрь 2020 года на базе 1-ого хирургического отделения ГБУЗРОД. Если в целом рак толстой кишки брать за 100\% , то среди них с диагнозом: - $\mathrm{Cr}$ ректосигмоидного отдела- 21\%; -Cr восходящего отдела ободочной кишки- 20\%; -Cr нисходящего отдела ободочной кишки- 10\%; -Cr поперечного отдела ободочной кишки- 19\%; - $\mathrm{Cr}$ слепой кишки-15\%; $-\mathrm{Cr}$ сигмовидной кишки- $15 \%$. 


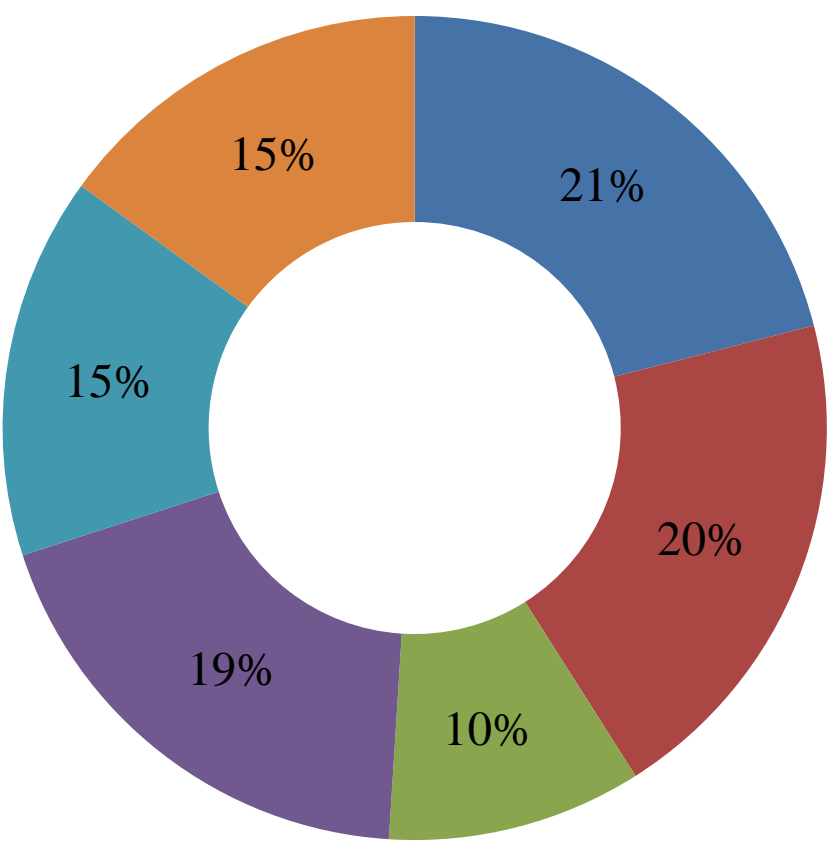

рак

ректосигмоидного отедала

- рак восходящего отдела ободочной кишки

рак нисходящего отедла ободочной кишки рак поперечного отдела ободочной кишки

рак слепой кишки

рак сигмовидной кишки

\section{Рис.1. Частота встречаемости рака толстой кишки по отделам}

Мы разделили все истории болезни на две группы: 1-пациенты, которым на раннем (2-3 месяца) послеоперационном периоде еженедельно проводили диагностику титра РЭА в венозной крови, их процент составляет 47\%; 2пациенты, которым не проводилась данная диагностика, процент данной группы 53\%. По данным исследования, было выявлено, что у $35 \%$ из 47, относящихся к первой группе, на раннем доклинические этапе был выявлено прогрессирование злокачественного процесса, что позволило вовремя направить на дальнейшее химиотерапевтическое лечение или на лучевую терапию. У пациентов, относящимся ко второй группе, из 53\% у 33\% наблюдается прогресс, но определяется он уже на далеко зашедшей стадии, которая сопровождается яркой характерной картиной, с развитием канцероматоза. Онкологическое заболевание является одним из самых грозных заболеваний. Пациенты, узнав что у них онкология, зачастую боятся этого диагноза, что очень сильно влияет на их психоэмоциональное состояние и в конечном итоге на эффективность дальнейшей терапии. Поэтому так 
необходимо улучшение методов диспансеризации населения и взятие крови на определение уровня раково - эмбрионального антигена.

В результате нашего исследования, можно сделать вывод, что диагностическая значимость РЭА, особенно в послеоперационном периоде при раке толстой кишки, предельно высока. Так как при своевременном выявлении продолжения процесса, на раннем этапе можно подобрать соответсвующее лечение, и возможно, приостановить рост опухоли, что избавит пациента от инвалидизации, и печальной судьбы.

\section{Список литературы}

1. Агеенко, А. И. Рак. Расшифровка злокачественности / А.И. Агеенко. М.: Ниола-Пресс, 2015. - 128 с.

2. Альбицкий, Игорь Прогноз осложнений лучевой терапии рака простаты / Игорь Альбицкий. - М.: LAP Lambert Academic Publishing, 2015. $108 \mathrm{c}$.

3. Бердов, Б. А. Диагностика и комбинированное лечение рака прямой кишки / Б.А. Бердов, А.Ф. Цыб, Н.И. Юрченко. - Москва: Гостехиздат, 2017. $272 \mathrm{c}$.

4. Берштейн, Л. М. Онкоэндокринология / Л.М. Берштейн. - М.: Наука. Ленинградское Отделение, 2014. - 344 с.

5. Бронштейн, Б. Л. Рак толстой кишки / Б.Л. Бронштейн. - М.: Государственное издательство медицинской литературы, 2014. - 170 с.

6. Диагностика и лечение злокачественных новообразований: клинические протоко- лы / под ред. В. И. Чиссова. - М.: МНИОИ им. П.А. Герцена, 2013. - 599 с.

7. В. Камышников: Онкомаркеры. Методы определения, референтные значения, интерпретация тестов 